\title{
Research Article \\ Effects of Different Methods of Isolation on Volatile Composition of Artemisia annua L.
}

\author{
Danijela Vidic $\left(\mathbb{D},{ }^{1}\right.$ Amira Čopra-Janićijević, ${ }^{1}$ Mladen Miloš $\mathbb{D}^{2},{ }^{2}$ and Milka Maksimović $\left(\mathbb{D}{ }^{1}\right.$ \\ ${ }^{1}$ Department of Chemistry, Faculty of Science, University of Sarajevo, Sarajevo 71 000, Bosnia and Herzegovina \\ ${ }^{2}$ Faculty of Chemistry and Technology, University of Split, 21000 Split, Croatia \\ Correspondence should be addressed to Milka Maksimović; mmaksimo@pmf.unsa.ba
}

Received 31 May 2018; Revised 11 July 2018; Accepted 6 August 2018; Published 19 August 2018

Academic Editor: Federica Pellati

Copyright (c) 2018 Danijela Vidic et al. This is an open access article distributed under the Creative Commons Attribution License, which permits unrestricted use, distribution, and reproduction in any medium, provided the original work is properly cited.

\begin{abstract}
In order to determine influence of extraction method on volatile oil composition of Artemisia annua L., steam distillation, hydrodistillation, organic solvent extraction, and headspace sampling have been applied. The relative abundance of volatile compounds from the odorous aerial parts of A. annua, obtained by different extraction techniques, was analyzed by GC-MS. Exactly fifty constituents were identified. The leaf and flower essential oil yield ranged from 0.9 to $2.3 \%$ (v/w). Oxygenated monoterpenes were predominant in all samples ranged from $42.6 \%$ for steam-distilled fraction of petroleum ether extract to $70.6 \%$ for headspace of plant material. Essential oils isolated by steam distillation and hydrodistillation indicate that $A$. annua belongs to artemisia ketone chemotype with its relative content of $30.2 \%$ and $28.3 \%$, respectively. The principal constituent in headspace sample of plant material was also artemisia ketone (46.4\%), while headspace of petroleum ether extract had camphene (25.6\%) as the major compound. The results prove the combined approaches to be powerful for the analysis of complex herbal samples.
\end{abstract}

\section{Introduction}

Within the tribe Anthemideae of the family Asteraceae, with its nearly 100 genera, Artemisia is by far the largest and most distributed genus, comprising some 400-500 species including a number of which are important for their medicinal properties $[1,2]$.

The most famous among them is Artemisia annua L., sweet wormwood, a highly aromatic herb of Asian and Eastern European origin that is nowadays naturalized worldwide. This annual herbaceous plant with a strong fragrance is known as the only source of the traditional Chinese herbal medicine Qing Hao, which has been used for over 2000 years to alleviate fevers and to stop malarial attack. These ethnopharmacological applications led to the isolation of the sesquiterpene lactone endoperoxide artemisinin present in the aerial parts of the plant $[3,4]$.

This compound of a cadinene skeleton with a unique 1,2,4-trioxane segment, responsible for antimalarial activity of A. аnnua, was discovered in 1972 by Professor Tu's team. This discovery was recognized by her receipt of the Nobel
Prize in medicine in 2015 [5, 6]. Due to this discovery, as one of the most important achievements for the natural products chemistry in last decades of the twentieth century, A. annua is now rated as one of the top ten industrial crops of the modern world.

Nowadays, artemisinin and semisynthetic derivatives of similar structure are being developed as a novel class of peroxide-based antimalarial drugs, with activity against multidrug-resistant strains of Plasmodium falciparum and cerebral malaria $[7,8]$. Furthermore, the use of artemisininbased combination therapy (ACT) is widely recommended by World Health Organization (WHO) in different countries as the most effective one against the drug-resistant parasites. Some data shows that artemisinin becomes cytotoxic in the presence of ferrous iron [9].

Following the discovery of the important anti-mullerian sesquiterpene lactone artemisinin from A. annua L., there have been extensive phytochemical investigations of this species resulting in the description of many compounds such as terpenoids and flavonoids, as the most characteristic secondary metabolites. More than 150 natural products were 
reported to belong to different chemical structure types [10].

Artemisia annua is also valued for its essential oil of which the characteristic sweet aroma has been described as grassy, fresh, and bitter with a camphoraceous nuance. The commercial significance of the essential oil is limited, but it is sometimes used in fragrances, in perfumery, and cosmetic products. The essential oil has been reported to possess antimicrobial [11], antioxidant [12, 13], leishmanicidal [14], and cytotoxic [15] activities.

The essential oil composition of this medicinal plant, which exhibits a chemical variability, has been studied thoroughly and hundreds of components have been identified up to date [16]. The great diversity was found in the essential oil components of $A$. annua with monoterpenes being principal constituents [10] that contribute to the characteristic fragrance of this medicinal species. The monoterpene fraction of the essential oil from A. annua is composed of a diverse array of structures from the prosaic, regular monoterpenes such as $\alpha$-pinene, 1,8-cineole, and camphor, to the rearranged, such as fenchol and camphene hydrate, and to the irregular, such as artemisia alcohol, artemisia ketone, and santolina triene which give the plant a sweet scent. Depending on the variety, dominant compounds were artemisia ketone and camphor [17-20], camphor and 1,8-cineole [21-23], $\alpha$-pinene and pinocarvone [24], and artemisia ketone and 1,8-cineole [17, 25]. The exception is a chemotype with phenolic compounds thymol and carvacrol as the principal constituents [26], and varieties with no artemisia ketone detected [27], and with oxygenated sesquiterpenes as the major constituents [28].

The present work is a continuation of our study on chemical composition of essential oil from A. апnиа of Bosnian origin [20,28]. Traditionally, this fragrant plant is used for crafting of aromatic wreaths, flavouring of spirits and insect repellent.

Previously we demonstrated that $A$. апnиa cultivated near Sarajevo, Bosnia, belongs to artemisia ketone-camphor chemotype and its essential oil shows antioxidant and antimicrobial activity [20].

In the present work, comparison of the volatile compounds from the leaves and flowers of the wild grown $A$. annua, obtained by different methods of isolation, steam distillation, hydrodistillation, organic solvent extraction, and headspace technique, was investigated.

\section{Experimental}

2.1. Plant Material. The aerial plant parts of Artemisia annua L. were collected from natural habitat in central part of Bosnia. Investigated plant was harvested in the full flowering stage and put to dry in ambient condition. A voucher specimen was deposited at the Faculty of Science, University of Sarajevo.

2.2. Chemicals and Reagents. All reagents were of the highest purity available and obtained from the Sigma-Aldrich Chemical Company (Germany).

\section{Materials and Methods}

3.1. Sample Preparation. Air-dried plant material was subjected to standard steam distillation (Sample B) and hydrodistillation (Sample C) (50 g for each), during $2 \mathrm{~h}$. The essential oils were extracted with dichloromethane and dried over anhydrous sodium sulphate.

Plant material was also extracted by Soxhlet extraction $(3 \mathrm{~h})$ with petroleum ether as a solvent. Solvent was removed using rotary evaporator (temperature of water bath was $30^{\circ} \mathrm{C}$ ) and crude extract was subjected to the standard steam distillation (Sample E), in order to isolate volatile components of the extract.

Floral and leaf aroma, of dry plant material (10 g) (Sample A), as well as scent of petroleum ether extract (Sample D), were collected using dynamic headspace sorption on Dräger charcoal tubes \#6728631 with sorption agent coconut shell charcoal; trapping time was $3 \mathrm{~h}$, at ambient temperature. Trapped volatiles were eluted with dichloromethane.

3.2. GC-MS Analysis. The analysis of volatile compounds was performed using two GC-MS instruments and two columns of different polarity. First GC-MS analysis was carried out on the Perkin Elmer Mass, fitted with a fused-silica PE5 (5\% phenyl methyl siloxane) capillary column (30 $\mathrm{m} \mathrm{x}$ $0.25 \mathrm{~mm}, 1 \mu \mathrm{m}$ film thickness), and coupled to a Turbo Mass Auto System XL. Column temperature was programmed from $55^{\circ} \mathrm{C}$ at $10^{\circ} \mathrm{C} / \mathrm{min}$ to $140^{\circ} \mathrm{C}$ held $1 \mathrm{~min}$ isothermal and then $10^{\circ} \mathrm{C} / \mathrm{min}$ to $245^{\circ} \mathrm{C}$. Helium was used as carrier gas $(1.1 \mathrm{~mL} / \mathrm{min})$. Other operating conditions were as follows: injector temperature, $240^{\circ} \mathrm{C}$; detector temperature, $280^{\circ} \mathrm{C}$; injection volume, $1 \mu \mathrm{L}$. Ionization of the sample components was performed in the EI mode, $(70 \mathrm{eV})$, with scan range 20 $555 \mathrm{amu}$, and scan time $1.60 \mathrm{~s}$.

The GC-MS analysis on the polar column was carried out using Hewlett Packard GC-MS system (GC 5890 series II; MSD 5971A, Hewlett Packard, Vienna, Austria). The fusedsilica HP-20 M polyethylene glycol column $(50 \mathrm{~m} \times 0.2 \mathrm{~mm}$, $0.2 \mu \mathrm{m}$ thickness) was directly coupled to the mass spectrometer. The carrier gas was helium $(1 \mathrm{ml} / \mathrm{min})$. The program used was $4 \mathrm{~min}$ isothermal at $70^{\circ} \mathrm{C}$, then was $4^{\circ} \mathrm{C} / \mathrm{min}$ to $180^{\circ} \mathrm{C}$, and was held $10 \mathrm{~min}$ isothermal. The injection port temperature was $250^{\circ} \mathrm{C}$, and the detector temperature was $280^{\circ} \mathrm{C}$. Ionization of the sample components was performed in the EI mode $(70 \mathrm{eV})$. The linear retention indices for all compounds were determined by injection of the sample with a solution containing the homologous series of $\mathrm{C}_{8}-\mathrm{C}_{24} n$ alkanes under the above conditions in order to calculate the retention indices using generalized equation [29].

The identification of the essential oil constituents was accomplished by comparing retention indices from the literature data [30] and mass spectra by computer library search (HP Chemstation computer library NBS75K.L, NIST/ EPA/NIH Mass Spectral Library 2.0 and Mass Finder 4 Computer Software and Terpenoids Library).

\section{Results and Discussion}

Chemical characterization of volatile profile of A. annua, using four different methods of isolation: headspace, steam 
distillation, hydrodistillation, and solvent extraction has been done.

Hydrodistillation (HD) was applied as one of the simplest conventional ways to separate the essential oil from different parts of the plants. Steam distillation (SD) used in this study is similar and standard method for essential oils isolation. However, the main restrictions of HD as well as of SD are as long extraction times, the possibility of the decomposition, and/or loss of heat-sensitive compounds during the extraction. In contrast, headspace method is a very facile, sensitive, and solvent-free sampling and concentration technique for the determination of volatile compounds without destroying plant material. In addition, petroleum ether was chosen for isolation of various compounds from plant material soluble in nonpolar solvent which is easy to remove after extraction in Soxhlet apparatus.

The yield of clear yellowish coloured hydro-distilled essential oil, sample B, and steam-distilled essential oil, sample C was $1.0 \%$ and $0.9 \%$, respectively, while sample E, obtained by extraction with petroleum ether as a solvent, followed by steam distillation, was recovered in yield of $2.3 \%$. The yield is expressed as \% of extracted essential oil relative to the mass of dry plant material.

Chemical composition of three distilled essential oils and two headspace samples was determined by detailed gas chromatography-mass spectrometry GC-MS analysis. The identification of the plant fragrance and other extractable plant components was performed using two GC columns, polar HP-20 and semipolar PE-5. Distribution of the volatile constituents, their RI indices, and relative amounts are presented in Table 1.

Exactly 50 components were identified in all five samples, many of which occurred only in amounts below $1 \%$. Three components, ethyl 2-methyl butanoate, santolina triene, cis3-hexenyl 2-methylbutanoate, were found only in sample A, isolated by headspace technique of dry plant material. Seven compounds were found in all samples: $\beta$-myrcene, 1,8-cineole, artemisia ketone, artemisia alcohol, camphor, $\beta$ caryophyllene, and (E)- $\beta$-farnesene, and among them the most abundant were irregular monoterpene artemisia ketone (16.5\%-46.4\%) and regular monoterpene camphor $(7.5 \%$ $24.0 \%)$.

The highest number of total identified constituents was 47 in the sample B, representing $96.1 \%$ of the essential oil. The lowest number of identified components (11) was in headspace sample D comprising $97.8 \%$ of the total components detected. When grouping the components into different terpenoid types, there were found eight monoterpenes hydrocarbons $(\mathrm{MH}), 17$ oxygenated monoterpenes (MO), 11 sesquiterpene hydrocarbons ( $\mathrm{SH}$ ), five oxygenated sesquiterpenes (SO), and one oxygenated diterpenes (DO). Most abundant compounds for all samples were $\mathrm{MO}$, ranged from $42.6 \%$ (sample E) to $70.6 \%$ (sample A).

All heat-involving isolation procedures have been shown to differentiate the volatile fraction profile as analyzed by GCMS. Although essential oils obtained by steam distillation and hydrodistillation showed prominent similarity in chemical composition, they still differ in quantitative composition, especially in their relative contents of the main constituents like camphor: $24.0 \%$ in sample B and $16.9 \%$ in sample C, respectively. Data on the essential oil composition of sample E, obtained by extraction with organic solvent followed by steam distillation, indicated the percentage concentration drop in terms of characteristic markers: artemisia ketone (16.5\%) and camphor (20.0\%) or absence of some compounds in the petroleum ether extract. The observed fact may be attributed to the effect of the heat applied; i.e., some of the compounds were degraded during distillation process or the concentration of compounds in the volatile fraction of the petroleum ether extract may be below the detection limit due to their loss during evaporation of the solvent.

Oxygenated sesquiterpenes (SO) were identified in all samples obtained by distillation process with caryophyllene oxide as the most abundant representative of this class (8.2\% in sample E), while these compounds were not detected in the headspace samples.

Headspace of plant material (A) and essential oil (B i C) were of artemisia ketone chemotype. In headspace sample of petroleum ether extract (D), the main component was camphene $(25.6 \%)$, while, in sample obtained by steam distillation of petroleum ether extract (E), the main component was camphor (20.0\%) and camphene was not detected. Four high volatile compounds, $\alpha$-pinene, camphene, sabinene, and $\beta$-pinene, comprising $43.7 \%$ of sample $D$, were not found in sample $\mathrm{E}$ where steam distillation was applied.

Comparing the emission from excised leaves and flowers and from crude petroleum extract of plant material, it can be concluded that number of components responsible for scent of plant material (sample A) are more numerous than volatiles emitted from petroleum ether extract (sample D). All 11 components identified in sample D were also present in sample A. Sample A is almost twice more heterogeneous than sample D, where 20 components comprised $96.5 \%$ of total identified constituents.

Literature survey revealed a few articles on headspace sampling of $A$. annua aroma performed by solid-phase microextraction (SPME). Comparing our results on the plant volatile profile with previously published data, there are great differences in both qualitative and quantitative composition. The variability of chemical composition could be effected by many factors, such as genotype, geographic location, cultural practices, used parts of the plant, and mode of extraction of volatiles used, so the types of major volatile compounds in shoots differ from those detected in roots of cultivated A. annua [31]. Headspace SPME analysis of artemisinin-rich A. annua cultivars showed the absence of artemisia ketone [32] known as a characteristic volatile biomarker of wild-type species [33].

\section{Conclusions}

The data on volatile profile of Artemisia annua growing wild, presented in this study, confirm the already observed for the essential oil, the relative percentages, however being different due to the different extractions and analytical protocols. Significant differences were found for GC pattern of headspace samples from that prepared by distillation. Application of nondestructive headspace method for extraction of 
TABLE 1: Volatile constituents of Artemisia annua L. obtained by different methods of isolation.

\begin{tabular}{|c|c|c|c|c|c|c|c|}
\hline \multirow[t]{2}{*}{ Compound } & \multirow[t]{2}{*}{$\mathrm{RI}^{\mathrm{a}}$} & \multirow[t]{2}{*}{$\mathbf{R I}^{\mathbf{b}}$} & \multicolumn{5}{|c|}{ Sample (\%) } \\
\hline & & & $\mathbf{A}$ & B & $\mathrm{C}$ & $\mathrm{D}$ & $\mathbf{E}$ \\
\hline Ethyl 2-methyl butanoate & 869 & & 0.3 & - & - & - & - \\
\hline Santolina triene & 910 & & 0.5 & - & - & - & - \\
\hline Artemisia triene & 929 & & - & 0.4 & 0.2 & - & - \\
\hline$\alpha$-Pinene & 937 & 1043 & 0.3 & $\mathrm{t}$ & - & 11.9 & - \\
\hline Camphene & 951 & 1061 & 6.5 & 0.8 & 0.6 & 25.6 & - \\
\hline Sabinene & 972 & 1117 & 0.5 & 0.2 & $\mathrm{t}$ & 6.2 & - \\
\hline$\beta$-Pinene & 976 & 1102 & $\mathrm{t}$ & $\mathrm{t}$ & - & $\mathrm{t}$ & - \\
\hline$\beta$-Myrcene & 984 & 1145 & 17.1 & 3.7 & 4.2 & 1.7 & 0.9 \\
\hline Yomogi alcohol & 997 & 1370 & - & 0.5 & 3.9 & - & - \\
\hline$p$-Cymene & 1025 & 1244 & - & $\mathrm{t}$ & $\mathrm{t}$ & - & - \\
\hline 1,8-Cineole & 1031 & 1193 & 8.5 & 5.3 & 5.4 & 18.3 & 0.3 \\
\hline Artemisia ketone & 1065 & 1330 & 46.4 & 30.2 & 28.3 & 24.5 & 16.5 \\
\hline cis-Sabinene hydrate & 1076 & 1524 & - & $\mathrm{t}$ & - & - & - \\
\hline Artemisia alcohol & 1087 & 1475 & 2.5 & 3.1 & 2.2 & 0.5 & 2.8 \\
\hline trans-Sabinene hydrate & 1100 & 1423 & - & 0.8 & 0.4 & - & 0.7 \\
\hline trans-Pinocarveol & 1141 & 1603 & - & 0.5 & 0.4 & - & $\mathrm{t}$ \\
\hline Camphor & 1151 & 1476 & 13.2 & 24.0 & 16.9 & 7.5 & 20.0 \\
\hline Pinocarvone & 1167 & & - & 0.7 & 0.4 & - & - \\
\hline Borneol & 1172 & 1657 & - & $\mathrm{t}$ & $\mathrm{t}$ & - & - \\
\hline Terpinen-4-ol & 1175 & 1560 & - & 0.7 & 0.7 & - & 1.5 \\
\hline p-Cymen-8-ol & 1181 & & - & $\mathrm{t}$ & $\mathrm{t}$ & - & $\mathrm{t}$ \\
\hline$\alpha$-Terpineol & 1187 & 1650 & - & 1.3 & 0.7 & - & 0.8 \\
\hline Myrtenal & 1209 & 1580 & - & 0.7 & 0.4 & - & - \\
\hline Myrtenol & 1210 & 1730 & - & 1.0 & 0.4 & - & - \\
\hline cis-3-Hexenyl 2-methylbutanoate & 1217 & & 0.1 & - & - & - & - \\
\hline Hexyl 2-methylbutanoate & 1219 & & - & 0.6 & 0.4 & - & 0.5 \\
\hline 3-Tetradecene & 1274 & & 0.2 & 0.2 & 0.2 & - & - \\
\hline p-Cymen-7-ol & 1280 & & - & $\mathrm{t}$ & $\mathrm{t}$ & - & - \\
\hline Piperitenone & 1342 & 1856 & - & 1.1 & 0.8 & - & - \\
\hline Eugenol & 1358 & 2091 & - & 0.9 & 1.2 & - & - \\
\hline$\alpha$-Copaene & 1384 & 1466 & - & 0.7 & 0.7 & - & 0.5 \\
\hline Phenyl methyl pentanoate & 1387 & 1813 & - & 0.1 & 0.4 & - & 0.5 \\
\hline$\beta$-Cubebene & 1390 & 1666 & - & 1.7 & 0.8 & - & - \\
\hline$\beta$-Elemene & 1396 & & - & 0.8 & 0.6 & - & - \\
\hline$\beta$-Caryophyllene & 1426 & 1565 & 0.1 & 3.1 & 3.9 & 1.3 & 1.2 \\
\hline$\alpha$-Humulene & 1456 & 1620 & $\mathrm{t}$ & $\mathrm{t}$ & 0.6 & - & - \\
\hline$(E)$ - $\beta$-Farnesene & 1458 & 1634 & 0.2 & 4.2 & 4.1 & 0.4 & $\mathrm{t}$ \\
\hline$\tau$-Selinene & 1476 & 1646 & 0.1 & 1.8 & 1.3 & - & - \\
\hline$\gamma$-Muurolene & 1478 & & 0.1 & $\mathrm{t}$ & $\mathrm{t}$ & - & - \\
\hline Germacrene -D & 1493 & 1689 & - & 0.6 & 0.6 & - & - \\
\hline$\beta$-Selinene & 1495 & 1675 & $\mathrm{t}$ & 0.4 & 0.3 & - & 1.0 \\
\hline Viridiflorene & 1497 & 1663 & $\mathrm{t}$ & $\mathrm{t}$ & $\mathrm{t}$ & - & - \\
\hline Isobornyl-3-methylbutanoate & 1513 & & - & $\mathrm{t}$ & - & - & 0.5 \\
\hline Caryophyllene oxide & 1590 & 1930 & - & 2.4 & 2.6 & - & 8.2 \\
\hline 1-epi-Cubenol & 1619 & 2006 & - & 0.7 & 0.8 & - & 1.8 \\
\hline Selina-3,11-diene-6- $\alpha$-ol & 1631 & & - & 0.8 & 0.6 & - & 2.7 \\
\hline Selin-11-en-4- $\alpha$-ol & 1649 & & - & 0.5 & 0.4 & - & 1.9 \\
\hline$\alpha$-Bisabolol & 1664 & 2164 & - & 0.4 & 0.5 & - & 1.4 \\
\hline Hexahydrofarnesyl acetone & 1779 & & - & 0.4 & 2.4 & - & 0.7 \\
\hline Phytol & 1970 & & - & 0.6 & - & - & - \\
\hline
\end{tabular}


TABle 1: Continued.

\begin{tabular}{|c|c|c|c|c|c|c|}
\hline \multirow[t]{2}{*}{ Compound } & \multirow[t]{2}{*}{$\mathbf{R I}^{\mathrm{a}} \quad \mathbf{R I}^{\mathrm{b}}$} & \multicolumn{5}{|c|}{ Sample (\%) } \\
\hline & & A & B & $\mathrm{C}$ & $\mathbf{D}$ & $\mathbf{E}$ \\
\hline Monoterpenes hydrocarbons (MH) & & 24.9 & 5.1 & 5.0 & 45.4 & 0.9 \\
\hline Oxygenated monoterpenes (MO) & & 70.6 & 69.9 & 60.9 & 50.8 & 42.6 \\
\hline Sesquiterpene hydrocarbons (SH) & & 0.5 & 13.3 & 13.0 & 1.7 & 2.6 \\
\hline Oxygenated sesquiterpenes (SO) & & - & 4.9 & 4.9 & - & 15.9 \\
\hline Oxygenated diterpenes (DO) & & 0.6 & 2.2 & 4.6 & - & 2.3 \\
\hline Others $(\mathrm{O})$ & & - & 0.6 & - & - & - \\
\hline Total & & 96.5 & 96.1 & 88.3 & 97.8 & 64.3 \\
\hline
\end{tabular}

$\mathrm{RI}^{\mathrm{a}}$, retention indices relative to $\mathrm{C}_{8}-\mathrm{C}_{24}, n$-alkanes on the PE- 5 capillary column; $\mathrm{RI}^{\mathrm{b}}$, retention indices relative to $\mathrm{C}_{8}-\mathrm{C}_{24}, n$-alkanes $\mathrm{HP}-20 \mathrm{M}$ capillary column; sample A: headspace of plant material of A. annua; sample B: essential oil isolated by steam distillation; Sample C: essential oil isolated by hydrodistillation; sample D: headspace of petroleum ether extract; sample E: steam distillation of petroleum ether extract; \%: relative percentage obtained from peak area; $\mathrm{t}<0.1 \%$. Percentages of dominant compounds are given in bold.

the volatiles is considered to prevent a damage of the thermalsensitive molecules, thus providing a better approach of the compounds primarily responsible for the characteristic odour of dry herb. Apparently, the content and composition of volatiles are greatly influenced by technique of isolation. The use of headspace proves to be crucial in order to provide reliable insight into Artemisia annua chemistry.

\section{Data Availability}

The data used to support the findings of this study are available from the corresponding author upon request.

\section{Conflicts of Interest}

The authors declare no conflicts of interest.

\section{Acknowledgments}

This work has been supported in part by Croatian Science Foundation under Project no. HRZZ-IP-2014-09-6897.

\section{References}

[1] C. W. Wright, Artemisia, Taylor \& Francis, London and New York, 2002.

[2] K. S. Bora and A. Sharma, "The genus Artemisia: a comprehensive review," Pharmaceutical Biology, vol. 49, no. 1, pp. 101-109, 2011.

[3] D. L. Klayman, "Qinghaosu (Artemisinin): An antimalarial drug from China," Science, vol. 228, no. 4703, pp. 1049-1055, 1985.

[4] Y. Tu, "The discovery of artemisinin (qinghaosu) and gifts from Chinese medicine," Nature Medicine, vol. 17, no. 10, pp. 12171220, 2011.

[5] X.-Z. Su and L. H. Miller, "The discovery of artemisinin and the Nobel Prize in Physiology or Medicine," Science China Life Sciences, vol. 58, no. 11, pp. 1175-1179, 2015.

[6] Y. Tu, "Artemisinin-A Gift from Traditional Chinese Medicine to the World (Nobel Lecture)," Angewandte Chemie International Edition, vol. 55, no. 35, pp. 10210-10226, 2016.
[7] U. Eckstein-Ludwig, R. J. Webb, I. D. A. Van Goethem et al., "Artemisinins target the SERCA of Plasmodium falciparum," Nature, vol. 424, no. 6951, pp. 957-961, 2003.

[8] P. M. O’Neill and G. H. Posner, "A medicinal chemistry perspective on artemisinin and related endoperoxides," Journal of Medicinal Chemistry, vol. 47, no. 12, pp. 2945-2964, 2004.

[9] N. P. Singh and H. Lai, "Selective toxicity of dihydroartemisinin and holotransferrin toward human breast cancer cells," Life Sciences, vol. 70, no. 1, pp. 49-56, 2001.

[10] X. T. Liang and W. S. Fang, Medicinal Chemistry of Bioactive Natural Products, John Wiley \& Sons, 2006.

[11] A. R. Bilia, F. Santomauro, C. Sacco, M. C. Bergonzi, and R. Donato, "Essential oil of Artemisia annua L.: an extraordinary component with numerous antimicrobial properties," EvidenceBased Complementary and Alternative Medicine, vol. 2014, Article ID 159819, 7 pages, 2014.

[12] F. Juteau, V. Masotti, J. M. Bessière, M. Dherbomez, and J. Viano, "Antibacterial and antioxidant activities of Artemisia annua essential oil," Fitoterapia, vol. 73, no. 6, pp. 532-535, 2002.

[13] Y. Wu, X. Jiang, L. Zhang, and Y. Zhou, "Chemical Composition and Biological Activities of Volatile Oils in Different Periods of Growth of Artemisia annua L. from China," Journal of Essential Oil Bearing Plants, vol. 20, no. 5, pp. 1320-1330, 2017.

[14] M. Islamuddin, G. Chouhan, M. Y. Want et al., "Leishmanicidal activities of Artemisia annua leaf essential oil against Visceral Leishmaniasis," Frontiers in Microbiology, vol. 5, 2014.

[15] E. Nibret and M. Wink, "Volatile components of four Ethiopian Artemisia species extracts and their in vitro antitrypanosomal and cytotoxic activities," Phytomedicine, vol. 17, no. 5, pp. 369374, 2010.

[16] G. D. Brown, "The biosynthesis of artemisinin (Qinghaosu) and the phytochemistry of Artemisia annua L. (Qinghao)," Molecules, vol. 15, no. 11, pp. 7603-7698, 2010.

[17] D. J. Charles, E. Cebert, and J. E. Simon, "Characterization of the essential oil of Artemisia annua L.," Journal of Essential Oil Research, vol. 3, no. 1, pp. 33-39, 1991.

[18] Y. Holm, I. Laakso, R. Hiltunen, and B. Galambosi, "Variation in the essential oil composition of Artemisia annua L. of different origin cultivated in Finland," Flavour and Fragrance Journal, vol. 12, no. 4, pp. 241-246, 1997.

[19] M. Mucciarelli, R. Caramiello, M. Maffei, and F. Chialva, "Essential oils from some Artemisia species growing spontaneously in North-West Italy," Flavour and Fragrance Journal, vol. 10, no. 1, pp. 25-32, 1995. 
[20] S. Ćavar, M. Maksimović, D. Vidic, and A. Parić, "Chemical composition and antioxidant and antimicrobial activity of essential oil of Artemisia annua L. from Bosnia," Industrial Crops and Products, vol. 37, no. 1, pp. 479-485, 2012.

[21] A. Ahmad and L. N. Misra, "Terpenoids from Artemisia annua and constituents of its essential oil," Phytochemistry, vol. 37, no. 1, pp. 183-186, 1994.

[22] B. R. R. Rao, K. V. Syamasundar, and R. P. Patel, "Chemical Profile Characterization of Artemisia annua L. Essential Oils From South India Through GC-FID and GC-MS Analyses," Journal of Essential Oil Bearing Plants, vol. 17, no. 6, pp. 12491256, 2014.

[23] H. J. Woerdenbag, R. Bos, M. C. Salomons, H. Hendriks, N. Pras, and T. M. Malingré, "Volatile constituents of Artemisia annua L. (Asteraceae)," Flavour and Fragrance Journal, vol. 8, no. 3, pp. 131-137, 1993.

[24] M. R. Tellez, C. Canel, A. M. Rimando, and S. O. Duke, "Differential accumulation of isoprenoids in glanded and glandless Artemisia annua L," Phytochemistry, vol. 52, no. 6, pp. 10351040, 1999.

[25] R. Donato, F. Santomauro, A. R. Bilia, G. Flamini, and C. Sacco, "Antibacterial activity of Tuscan Artemisia annua essential oil and its major components against some foodborne pathogens," LWT-Food Science and Technology, vol. 64, no. 2, pp. 1251-1254, 2015.

[26] S. Satar, "Chemical characterization of essential oils from mongolian species of the Genus artemisia L.", Die Pharmazie, vol. 41, no. 11, pp. 819-820, 1986.

[27] S. C. Gouveia and P. C. Castilho, "Artemisia annua L.: Essential oil and acetone extract composition and antioxidant capacity," Industrial Crops and Products, vol. 45, pp. 170-181, 2013.

[28] D. Vidic, S. Ćavar Zeljković, M. Dizdar, and M. Maksimović, "Essential oil composition and antioxidant activity of four Asteraceae species from Bosnia," Journal of Essential Oil Research, vol. 28, no. 5, pp. 445-457, 2016.

[29] H. van Den Dool and P. Dec. Kratz, "A generalization of the retention index system including linear temperature programmed gas-liquid partition chromatography," Journal of Chromatography A, vol. 11, pp. 463-471, 1963.

[30] R. P. Adams, Identification of Essential Oil Components by Gas Chromatography/Mass Spectroscopy, Allured, Carol Stream, Ill, USA, 1995.

[31] S. Reale, P. Fasciani, L. Pace, F. De Angelis, and G. Marcozzi, "Volatile fingerprints of artemisinin-rich Artemisia annua cultivars by headspace solid-phase microextraction gas chromatography/ mass spectrometry.", Rapid communications in mass spectrometry : RCM, vol. 25, no. 17, pp. 2511-2516, 2011.

[32] M. Nekoei, M. Mohammadhosseini, and H. Akhlaghi, "Chemical composition of the volatile oils from the aerial parts of Artemisia annua L. (Asteraceae) by using head space solid phase microextraction and hydrodistillation methods prior to gas chromatographic-mass spectrometric determination: A comparative investigation," Journal of Essential Oil Bearing Plants, vol. 15, no. 6, pp. 926-933, 2012.

[33] A. R. Jassbi, R. Miri, and I. T. Baldwin, "Comparative hydrodistillation and headspace SPME-GC-MS analysis of volatile constituents of roots and shoots of Artemisia annua and Artemisia sieberi," Chemistry of Natural Compounds, vol. 49, no. 6, pp. 1148-1153, 2014. 

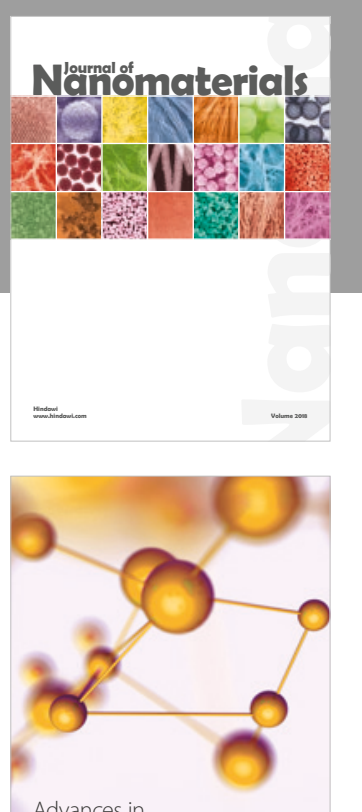

Physical Chemistry
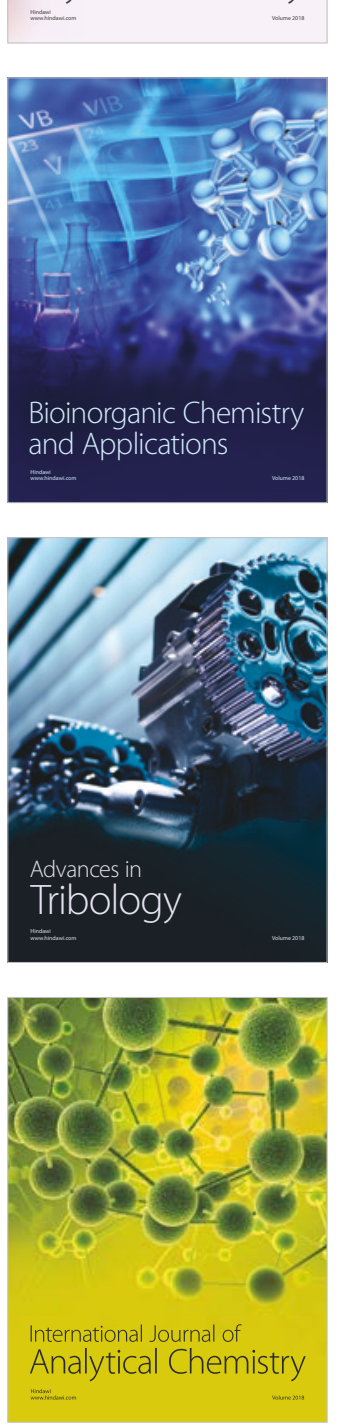

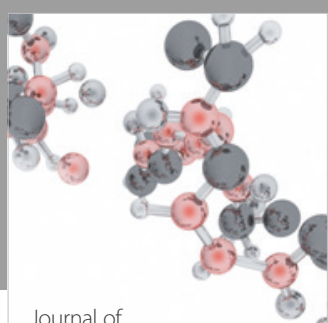

Analytical Methods

in Chemistry

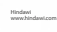

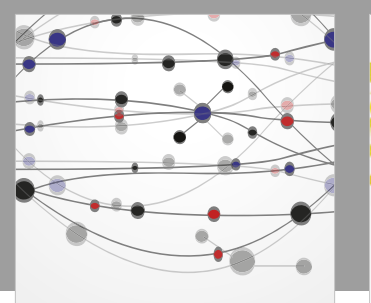

The Scientific World Journal

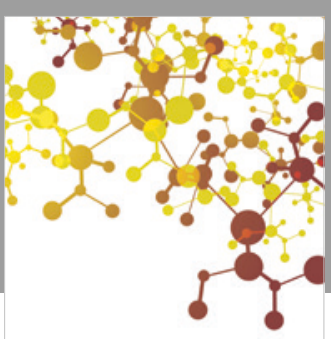

Journal of

Applied Chemistry
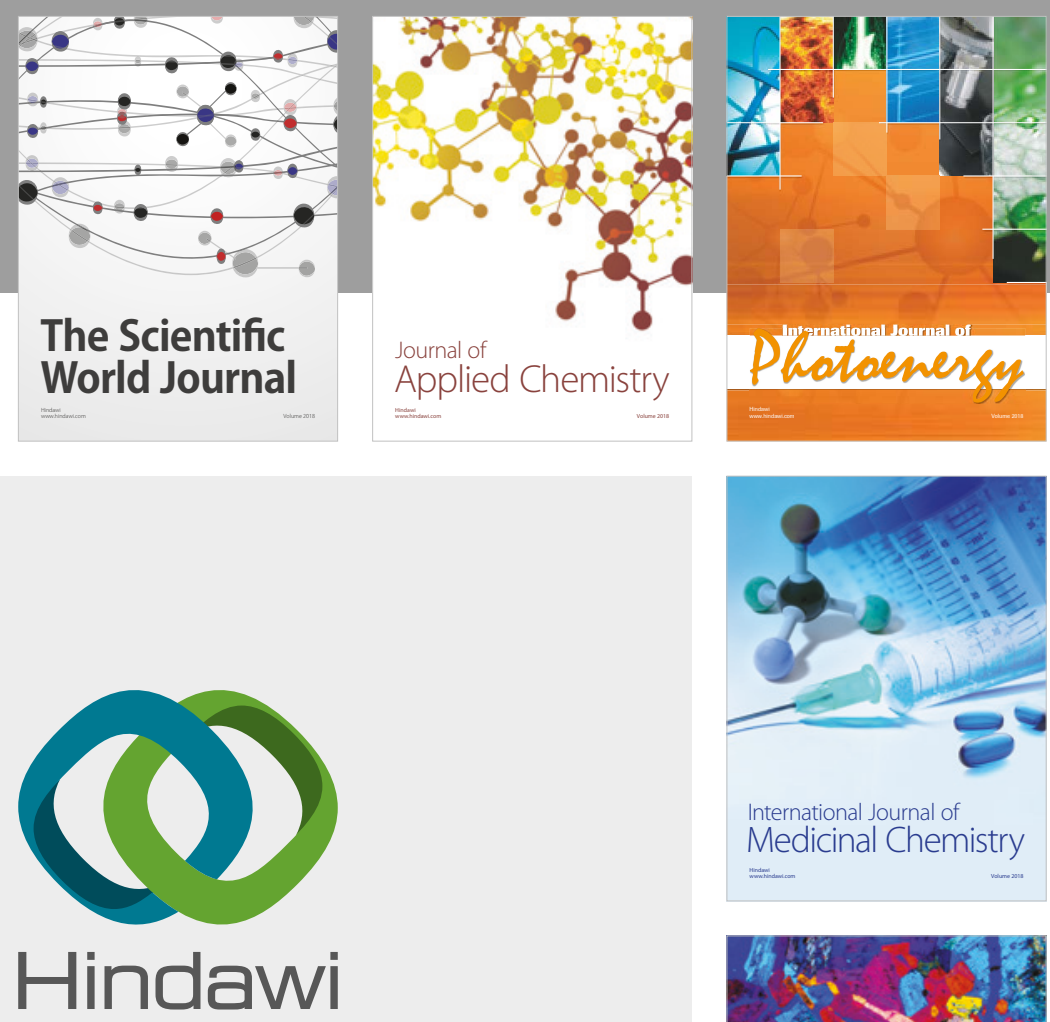

Submit your manuscripts at

www.hindawi.com
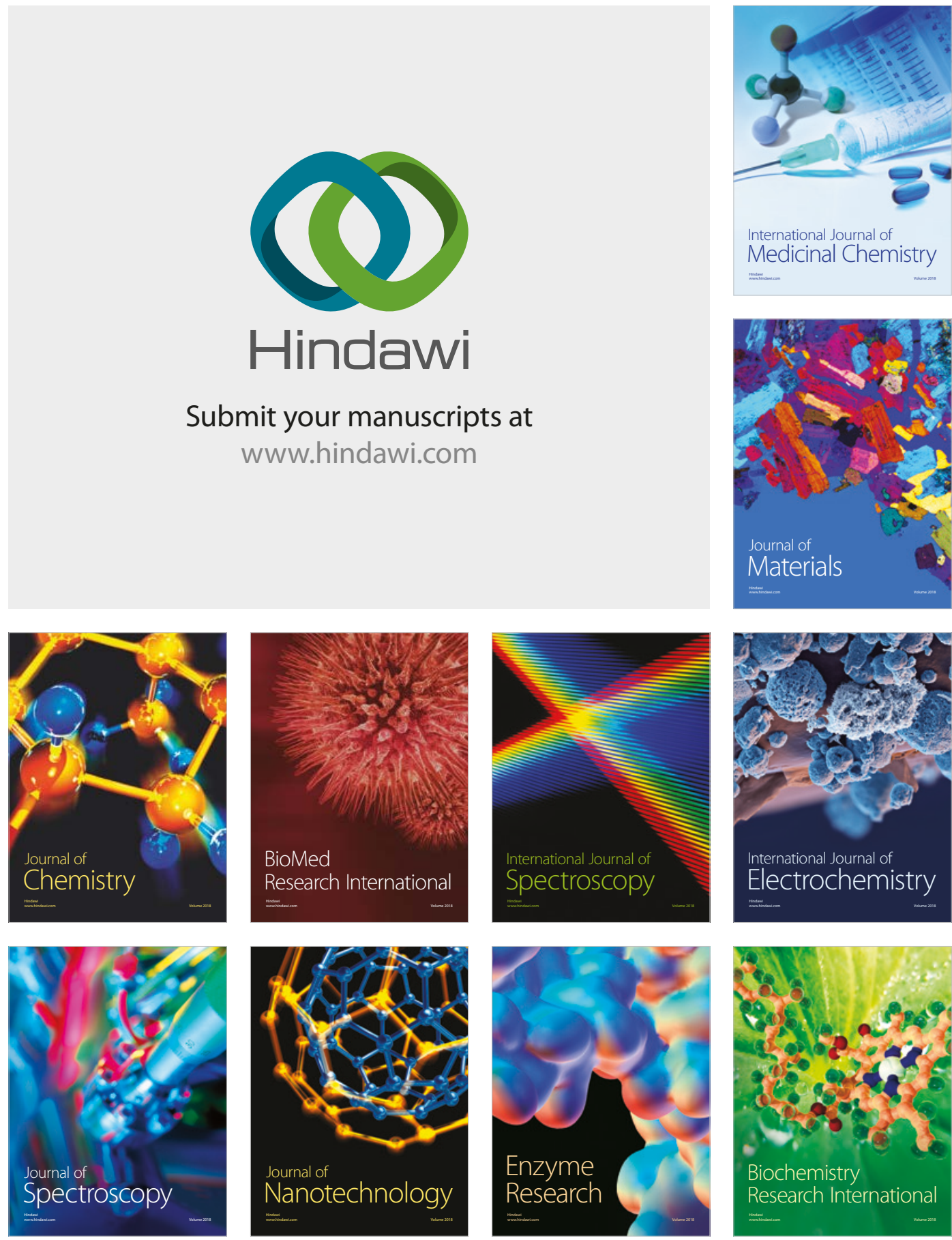
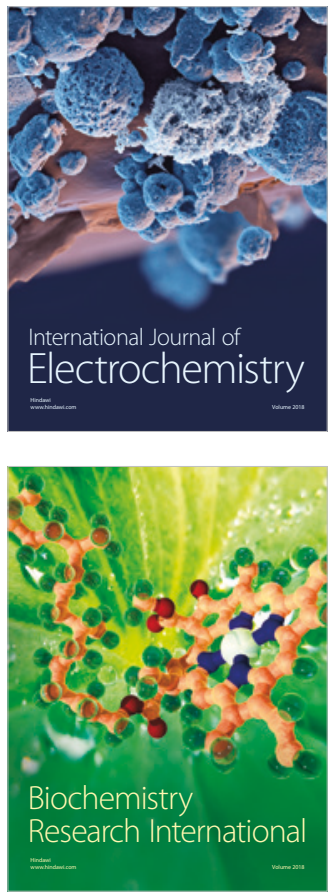